\title{
И. И. Филиппова
}

\section{Поздние произведения А. А. Пластова: образы и смыслы}

\begin{abstract}
Аннотация: анализ поздних произведений А. А. Пластова выявляет их основные образные и смысловые акценты. Внутренняя гармония, свойственная произведениям мастера, не исчезает под натиском новых веяний в общественной и художественной жизни страны. Работы последнего десятилетия жизни Пластова отражают суть его мировоззренческих установок. Сюжетная наполненность, выбор тем, жанровые предпочтения в его творчестве неразрывно связаны с решением живописных задач. Выступавиий против этюдности в картине, художник в некоторых поздних произведениях использует выразительные возможности быстрой работы с натурой. В статье особое внимание уделено работе художника над портретами и картинами «Бабушка Катерина и Таня Юдина» «Смерть дерева», «Слепые», «Апрель», особенностям их композиционного и живописного решения. В поздних произведениях отражается мировоззрение мастера, где царят традиционные для русской культуры религиозные и эстетические взгляды, основанные на целостном восприятии мира.
\end{abstract}

Review: Analyzing Arkady Plastov's late works, we can define the main images and meanings there. Internal harmony typical for work by this master, does not disappear under the influence of new ideas and events in the country's social and art life. Work created by Plastov during his last ten years of life reflected his attitude to the word. Narrative, selected topics and his preferences in genres were closely connected to his art goals. Opposing to sketches in painting, the artist used expressive opportunities of 'fast work with nature' in some of his late works. The author of the article pays special attention at such Arkady Plastov's portraits and paintings as 'Grandma Katerina and Tanya Yudina', 'Death of the tree', 'The Blinds' and 'April'. In his late paintings, Arkady Plastov shared his own perception of the world that is based on traditional Russian religious and esthetical views and holistic perception of the world.

Ключевъе слова: искусствоведение, А. А. Пластов, религиозные основы творчества, христианская система ценностей, традиционный крестьянский быт, композиционная структура, образносмысловые акценты, слепые, дети в искусстве, живопись.

Keywords: art history, Arkady Plastov, religious grounds of creative work, Christian system of values, traditional peasant life, composite structure, emphasis on image and meanings, blind, children in art, fine art.

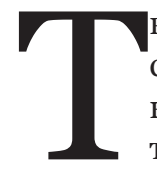
ворчество Аркадия Александровича Пластова(1893-1972)-однаизсамыхяркихстраниц в истории отечественного искусства тридцатых-шестидесятых годов XX века. Ни одна публикация по истории живописи советского периода не обходит своим вниманием его хрестоматийные произведения 1930-х - начала 1950-х гг. - «Колхозный праздник» («Праздник урожая») (1937), «Купание коней» (1937), «Стадо» («На пастбище») (1938), «Фашист пролетел» (1942), «Сенокос» (1945), «Жатва» (1945), «Первый снег» (1946), «Колхозный ток» (1949), «Ужин трактористов» (1951), «Родник» (1952). Работы же конца 1950-х и 1960-х годов, как правило, остаются за рамками исследований, историки искусства, следуя логике хронологического способа в изложении материала, сосредотачиваются на анализе новых тенденций и направлений, новых именах и актуальных выставках. Поэтому поздние картины Пластова остаются в тени «сурового стиля» и мощных фигур молодых шестидесятников.
Невозможно согласится с авторами, характеризующими последний этап творчества художника, как «реквием по прошлому, со всеми его иллюзиями и надеждами», утверждающими, что «смерть И. В. Сталина и хрущевские метания подорвали идейную основу живописи А. А. Пластова» ${ }^{1}$

Шестидесятые годы стали для Пластова периодом, когда, наряду с осуществлением давних замыслов и продолжением работы в привычных направлениях, подводится определенный итог пройденного пути в искусстве. Образному строю большинства его произведений конца 1950-х - 1960-х гг. свойственны внутренняя уравновешенность, тишина и покой. В них чувствуется глубокая вера художника в гармоничность мироздания. В этом Пластов не изменяет себе никогда. Особенно остро такие настроения ощущаются в детских портретах художника. В это время он много пишет сосед-

${ }^{1}$ Кузнецов В. Н. Аркадий Александрович Пластов и идеология позднего сталинизма // Творчество А. А. Пластова в контексте культуры XX века. - Ульяновск: УОХМ, 2004. С. 26. 
ских ребятишек и подрастающего внука - «Люда Шарымова», «Детский портрет (Внук рисует)», «Портрете внука (У окна)». Серьезная сосредоточенность, внимательные взгляды моделей - для Пластова значительны в своей простоте и безыскусности. В них все наполнено внутренней энергией и теплотой.

Двойной портрет «Бабушка Катерина и Таня Юдина» (пер. пол. 1960-х) необычен для Пластова. Подобное композиционное решение в портретном наследии художника - редкость. Сопоставляя в едином картинном пространстве два образа - старости и детства - Пластов создает одно из самых пронзительных своих произведений, отразившее его трепетное отношение к этим разным возрастам. Простота и безыскусность содержательной стороны портрета кажущаяся. Пластов очень тщательно выстраивает фон - старые фотографии, висящие на стене комнаты, создают атмосферу, настраивающую на воспоминания. Ощущение печали было бы подавляющим в работе, если бы не фигура девочки. Таня Юдина здесь становится воплощением образа любви и нежности, продолжения жизни. Мотив преемственности поколений не редко используется художниками, как безусловный символ вечности жизни, гармонии мироздания или зримое воплощение ответа на вопрос о смысле жизни.

Пластов таким образом строит композицию, что кажется, будто фигурка ребенка сюда попала случайно, словно художник намеревался писать лишь бабушку Катерину, а девочка, присевшая рядом, вовсе и не должна была ему позировать. Но, оказавшись подле любимого человека, так и осталась сидеть рядом до конца сеанса.

Размышляя о начале и конце жизненного пути человека, Пластов использует определенный набор метафор, который позволяет донести до зрителя волнующие его вопросы бытия. При всем разнообразии ассоциаций, смысловых установок и сложности образных решений, мастер остается верен главной линии всей свой жизни в искусстве, сформулированной им в одном из писем: «Такая практика у меня и в моем творчестве: ни одну картину я не написал, не проверив тысячекратно то, что собираюсь написать, что это - правда, и только правда, и иного не может быть ${ }^{2}$.

«Смерть дерева» (1962) - произведение, в котором звучит та же тема, что и в портрете бабушки Катерины и Тани Юдиной. Контекст сюжета в «Смерти дерева» выступает на первый план, преображаясь в текстуальную основу. Простота метафоры

\footnotetext{
${ }^{2}$ «Радостью бьется сердце...» // Художник. - 1972. - №11. - C. 31 .
}

не делает ее легковесной, напротив, благодаря ей, эмоциональное напряжение образного решения картины переживается еще острее.

Бо́льшую часть холста занимает изображение листвы березы. Эта пульсирующая зеленая масса, заключающая в себе столько жизненной энергии, завораживает своей красотой. Пластов, покрывая поверхность холста многочисленными мазками, виртуозно чередует освещенные солнечным светом и таящиеся в тени листья. Художник прописывает каждый листочек отдельно; среди них, находящихся близко друг от друга, нет одинаковых по тону.

В композиционной структуре найдено необычное для Пластова решение. В схеме расположения основных фигур композиции «читается» перевернутый равнобедренный треугольник, таким образом, художник достигает яркого ощущения неустойчивости. Повторяемые диагонали - фигура молодого мужчины, ствол падающего дерева - заостряют динамичность сцены.

Солнечный свет, как главный жизнеутверждающий символ в творчестве Пластова, в «Смерти дерева» сглаживает трагичность сюжета. Играющий в листве старой березы, он воспринимается камертоном, гармонизующим полифонию красоты и гибели, молодости и старости.

Перенос акцентов в сюжетных мотивах на жизнь простого человека, его чувства и переживания, никак не связанные ни с его общественно-полезным трудом, ни с социальной ролью в коллективе, становится определяющим в искусстве Пластова периода шестидесятых годов. Несмотря на то, что Пластов даже теперь пишет работы большого формата, например, «В деревне (Кружка молока)» (1961-62) или «Солнышко» (1965-66), они далеки от «шумных» композиций тридцатых-пятидесятых годов. Словно художник устал от подобного рода тем и сюжетов, исчерпав для себя их возможности. Причем, мы не можем говорить о таком «повороте» для советского искусства в целом, не можем назвать его тенденцией или ключевым направлением. Молодое поколение представителей, в частности, московской школы живописи, заявляют о себе работами далекими от лирики бытовой картины, выдвигающей на первый план частную жизнь простого человека. Понимание ценности человеческой жизни, как таковой, придет к ним чуть позже. А в начале шестидесятых В. Попков пишет «Строителей Братска» (1960-61), П. Никонов - «Наши будни» (1960), Н. Андронов - «Плотогоны» (1961). Безусловно, поэтика произведений этого ряда далека от генеральной линии искусства тридцатых - пятидесятых годов, но, так или иначе, она направлена на создание нового, но все же 
официально «одобренного» романтического мифа о «строителях коммунизма».

Для Пластова шестидесятые годы становятся временем осмысления прожитых лет, временем воспоминаний и острого понимания конечности человеческой жизни. В образной структуре произведений последнего десятилетия творческого пути живописца, эти настроения занимают не последнее место.

Художник несколько лет работает над волнующей его темой - «Слепые». Существует несколько вариантов композиции этой работы - «Слепые» (середина 1950-х-1967), «В старой Прислонихе (Слепые)» (1966-1968). Среди акварельных эскизов и набросков Пластова множество подготовительных материалов к картинам. Один из них, датированный 1951 г., подписан - «Ради Христа», тем самым Пластов подчеркивает, тема слепых, для него, имеет в основе христианскую заповедь о милосердии. Неслучайно, в своем замысле художник колеблется между двумя вариантами его воплощения, первый - через символику мотива дороги, второй - через сюжет о нищих, просящих милостыню. Каждый из вариантов для художника значителен по-своему. «Тема дороги имела в русской культуре особый сокровенный смысл, поскольку воспринималась в связи с христианским представлением о земной жизни как пути в вечность ${ }^{3}$, а милосердие - одно из важнейших качеств православного христианина, всегда было мерилом его нравственной чистоты и духовной зрелости.

Пластов был человеком верующим, мало того, получившим начальное богословское образование. За долгие годы жизни, ему не раз приходилось идти на компромиссы в самых разнообразных ситуациях. Но они не коснулись его духовной жизни. В вопроcax, имеющих для него принципиальное значение, Пластов был непримирим ${ }^{4}$. Даже то, как он излагает свои суждения в письмах, подтверждает явную религиозность их автора: «живу и делаю все наобум, как бог на душу положит...», «... я бы не знал, как благодарить бога...», «... и сколько это продлится - бог ведает», «... евангельский наказ: «толцыте и отверзется вам», «... уже никогда не появится на святой Руси» 5 . Даже извлеченные из контекста, эти речевые обороты, безусловно, важны для понимания тех ориентиров, на которые опирается Пластов. Но больше, чем слова, об этих ориентирах способны свидетельствовать его произведения.

\footnotetext{
${ }^{3}$ Третьяков Н.Н. Образ в искусстве. Основы композиции. Свято-Введенская Оптина Пустынь, 2001. С. 111.

${ }^{4}$ См.: Пластова Т. Аркадий Пластов. Православные истоки творчества // Русское искусство. - 2004. - № IV. - CC. 122-131. 5 «Радостью бьется сердце...» // Художник. - 1972. - № 11. - CC. $19-34$.
}

Работы последнего десятилетия жизни Пластова отражают суть его мировоззренческих установок. Однако не всегда замысел художника находил достойное живописное воплощение. Так случилось со «Слепыми». Несмотря на продолжительную предварительную работу, ни композиционное решение, ни повествовательно-содержательная сторона «Слепых» первого варианта, не удовлетворила художника. Второй вариант - «В старой Прислонихе», с его разработанностью жанровой основы, более тонкой живописной проработкой, убедительностью композиционного строя, - больше соответствовал замыслу Пластова. Художник упорно ищет приемлемое образное решение. Меняет направление движения странников, их возраст, разрабатывает пейзажный фон, дополняя его нюансами деталей, находит верные пространственные соотношения. И все же, достигая определенного результата, Пластов не заканчивает работу, но в ее эскизной незавершенности заключается особого рода ценность. Это, вероятно, чувствовал и сам художник, неслучайно, он подписывает холст, далекий от привычного для себя завершения.

Всегда выступавший против этюдности в картине, художник в некоторых поздних произведениях использует выразительные возможности быстрой работы с натурой. «Свадьба в старой Прислонихе» (1968) - работа показательная в этом отношении. Таинственность происходящего передается художником полумраком храмового интерьера, лишь фигуры невесты, жениха и священника освещены теплым светом венчальных свечей. Неравномерное освещение выхватывает из темноты силуэты фигур, отдельные лица, отражается на окладах икон. В глубоких тенях, передавая особое качество света, Пластов использует оттенки синего, красного и зеленого, отчего фигуры присутствующих в церкви не сливаются друг с другом. Художник «держит» форму каждого отдельного предмета композиции.

Романтизм этой сцены перекликается с похожей композицией - «Венчание» (1960-е). В ней так же, как и в «Свадьбе», Пластов замечательно передает своеобразное освещение в храме, но подругому строит пространство композиции, уделяя внимание не столько героям своего повествования, сколько соборному убранству. В этюде «Служба на Страстной» (1950-е) мерцание свечей в руках молящихся освещает их лица, создавая атмосферу благоговейной тишины и покоя.

Особая притягательность церковного интерьера для художников многих поколений, не раз отмечалась историками искусства. Красота православного храма не оставляла равнодушными ни И. Репина, ни В. Серова, ни А. Рябушкина, ни многих других. 
Каждый видел ее по-своему. Пластова привлекала не только, выразительность храмового пространства, но и переживания людей, пришедших в церковь. Это очень хорошо ощущается в акварельных работах, выполненных в разные годы. Выразительные лица прихожан - девушек, стариков и старух - Пластов пишет по памяти, придя из храма. В большинстве акварельных работ, выполненных под впечатлением от посещения церкви, художник с упоением передает игру света и тени, неизменно его привлекавшую. Горящие свечи, лампады, сверкающие ризы икон - во всем видится ему малая толика чудесного фаворского света, озаряющая земной путь человека. Церковный свет, свет Дома Божия на земле - символичен. Традиционность этой символики имеет давние истоки и строится на богословском понимании света, но в любом случае воспринимается как противопоставление тьме. В русской литературе образ свечи, особенно в произведениях Достоевского, играет немаловажную роль. Нередко герои Достоевского описываются со свечами в руках, символизирующими их внутреннюю духовную жизнь.

Вариации изображения огня, или, точнее, эффектов освещения, привлекательны для Пластова своей живописной выразительностью. Так, в картине «Костер в поле» (1968-69) Пластов наблюдает за лицами детей, сидящих вокруг вечернего костра, за тем, как близость огня изменяет цвет картофельных клубней; ему интересно сопоставление цветовых различий теплого воздуха рядом с костром и прохлады осеннего вечера вдали от него.

Среди редких у Пластова зимних пейзажей «Зима. Стожок» (1968) выделяется особой поэтичностью. Почти сливающееся с заснеженной землей небо, угасающие в дымке метели силуэты дальних деревенских домов, покосившиеся жерди изгороди, сбившиеся вокруг сена животные, сорока, сидящая на шесте, лошади, тянущие свою ношу - все погружено в снежную мглу. В этой работе, далекой от эффектности солнечных летних пейзажей, воплотилось свойственное художнику качество увидеть поэзию в обыденном. Почти монохромное цветовое решение разработано тончайшей нюансировкой. Пластов мастерски решает живописную задачу передачи снежного пространства. Совсем по-другому написан «Зимний вечер» (вторая пол. 1960-х). Отблески яркого закатного неба отражаются на снегу, контрастные силуэты скачущих лошадей, создают ощущение тревоги. Пластов замечательно передает свежесть морозного воздуха. Здесь художник иначе, чем в «Стожке», пишет снег - поверх глубоких голубых тонов он накладывает розоватые, лиловые с охрой мазки, которые вновь перекрывает сочными сине-голубыми.
Пейзажное пространство лежит в образной основе «Мартовского солнца» (1969). Особое, весеннее освещение деревенской улицы, влажный подтаявший снег, кромка голубого неба, все это звучит фоном в сюжете о наступающей весне, предчувствие которой в мельчайших подробностях повествования - сквозь распахнутые ставни бревенчатого дома мы видим кота, наблюдающего за петухом и курами, рядом греется на солнце коза, девочка осторожно ступает по бревну, перекинутому через первый ручей. Настроение покоя и ощущение звенящего весеннего воздуха передано в этой работе не только точно найденной колористической гаммой, но деталями, раскрывающими авторское отношение к происходящему.

Детские персонажи имеют первостепенное значение во многих композициях Пластова 1960-х годов. В «Пастушонке» (1964-1966), в картинах «Мама» (1964) и «Апрель» (1964-65) они определяют образно-смысловую наполненность полотен.

Художник много раз обыгрывал композицию с мальчиком-пастушком. Об отдыхе ребенка, проделавшего путь с многочисленным стадом до пастбища, художник рассказывает с проникновенной любовью, это чувствуется по тщательно отобранным повествовательным деталям - отброшенные в сторону ботинки, лежащая в золе картошка, берестяной кулек с ягодами, бережно уложенный в фуражку, хлеб на белой тряпице, собака, нашедшая что-то в траве, - все эти подробности важны для Пластова, ведущего рассказ о вполне конкретном человеке. В привычном для художника ключе решается пространство картины, глубокое и бесконечно длящееся, где взгляд, переходя от плана к плану, останавливается лишь на самом существенном. Пластов более мягко, общо́ пишет пейзаж, здесь даже трава первого плана не так детально прописана, как в «Жатве» или «Летом». Его внимание сосредоточено на мальчишке, вернее, взрослом ребенке, уверенном и самостоятельном, чувствующим собственную значительность, свободном и таком трогательном в своей простоте.

Вспоминая множество детских образов в работах Пластова, обращаешь внимание на то, что художник никогда не пишет их в момент игры. Они либо позируют для портретов, сын и внук - изображаются рисующими, либо помогают взрослым - на току, в поле и так далее. Исключением является «Апрель» (1964-70), где девочки, взявшись за руки, пляшут в хороводе, а чья-то младшая сестренка наблюдает за ними со стороны, вероятно, не принятая в их игру - «слишком мала́я». При всей непритязательности сюжета, простоте композиционного построения и цветовой гармонии, картина вызывает непреодолимое чувство тревоги. 
Пластов «выстраивает» это навязчивое ощущение, изображая танцующих девочек на фоне стены заброшенного храма. Его заколоченные окна, разбитый и покосившийся фонарь, пеньки спиленных деревьев - создают настроение безысходной тоски и уныния. Ассоциативный ряд, который читается в метафорах Пластова, очевиден. Его беспокоит утрата традиционного уклада жизни, уходящие в прошлое, казалось бы, незыблемые ценности и, как следствие, духовная пустота и потеря нравственных ориентиров.

Пластов пытается противостоять невежеству, отсутствию веры и идеалов доступными ему способами. Кинорежиссер М. И. Ромм вспоминал о выступлении Пластова на встрече с Н. С. Хрущевым в 1963 году в Кремле: «И такую он стал картину деревни рисовать, все поддакивая Хрущеву и говоря, - «Спасибо вам, Никита Сергеевич», - клуба нет, спирт гонят цистернами, все безграмотные, в искусстве ничего не понимают /.../ Такую картину постепенно обрисовал, что жутко стало /.../ И по сравнению с этим рассказом и «Вологодская свадьба» и «Матренин двор» просто показались какой-то идиллией... /.../ И хоть смеялись во время его выступления, когда он кончил, как-то стало страшновато /.../ » $^{6}$.

На самом деле, отношение художника к реалиям повседневности, не влияет на его мировоззренческие установки, он остается романтиком и идеалистом, опираясь в своих убеждениях на любовь, которая всегда считалась источником веры и религиозности.

Для Пластова современная действительность, как объект художественного воплощения, отступает на второй план. В вечном стремлении к идеалу, красоте и гармонии, он находит опору в собственных воспоминаниях, старине, предании. Лирическая гармония жизненного уклада старой России господствует в замыслах Пластова этого периода. Эстетика традиционного крестьянского быта, с ее неповторимым пониманием красоты, вбирающим в себя не только прикладную составляющую, но и духовно-нравственный аспект существования человека, находит воплощение в поздних произведениях художника. Его волнуют вечные ценности - семья, материнство, труд на собственной земле, милосердие, нравственная чистота и «примиряющее чувство лада».

В образах прекрасного прошлого художнику видится утраченное - красота непреходящих истин, позабытых за долгие годы «битвы за урожай». Поэтому-то он долгие годы работает над темой слепых, отсюда же и сюжет картины «Из прошло-

\footnotetext{
${ }^{6}$ Цит. по: Козлов Ю., Авдонин А. Жизнь и судьба Аркадия Пластова. Документальный очерк. - Ульяновск: Симбирская книга, 1992. С. 92.
}

го» (1969-70), созданной в самом конце жизненного пути. В этой картине нашли отражение самые сокровенные мысли художника о той идеальной основе бытия, о которой грезится в благостных снах, уносящих в далекое детство, где все наполнено безмятежностью и тишиной, всепоглощающей любовью и нежностью.

В каких-то отдельных составляющих композиция «Из прошлого» перекликается с «Жатвой», этот отзвук, словно камертон, настраивает зрителя на знакомую тональность, определяющую для художника ее значимость. Но в этой звуковой организации Пластов находит совсем иные гармонические сочетания. Разработка композиционной структуры усложняется - весь первый план заполнен фигурами и предметами, рисунок которых находится в тесной взаимосвязи друг с другом; волнообразная линия верхней части композиции повторена у нижней кромки холста. Дополнительную организацию ей придает распределение темных и светлых тонов в колористическом решении картины - сочетание розоватого полога зыбки слева и белой лошади справа разделяются темными пятнами - фигурой жеребенка и частью телеги. Цветовые акценты красного и синего поддерживаются отголосками этих тонов по всей поверхности красочного слоя - розоватыми рефлексами на голубой рубахе мужчины и крупе лошади, стальным оттенком на колесах телеги, сложным цветовым решением в живописи неба. На сочетании диагоналей, набегающих друг на друга линий рисунка фигур и предметов, создается общий ритм композиции. Этот ритм, строго распределенный и тщательно выверенный, придает ей (композиции) характер песенного распева, с его непрерывностью, повторяемостью, разнообразием подголосков.

Фон картины - созревшее хлебное поле, с пшеничными снопами на дальнем плане и колючим жнивьем снятых колосьев, расстилающимся ковром вокруг главных персонажей. Он является гармонизующим началом в колорите жанровой сцены и наделяется символическим значением: хлеб - то, что называют золотом, он - главное богатство крестьянина, в его достатке - залог благополучия. То есть для Пластова трактовка пейзажа существует в тесном единстве с традиционной системой крестьянского мировоззрения, ценностные ориентиры которой основаны на глубоком взаимовлиянии человека и природы. На этом выстраивается вся система образных связей в жанровых картинах Пластова, а по утверждению Н. Лосского: «У русских крестьян способность к религиозному опыту проявляется в их восприятии положительных аспектов природы, как творения Божия»7. Стоит

7 Лосский Н.О. Характер русского народа. Книга первая. Посев, 1957. С. 24. 
только представить, что персонажи Пластова лишены пейзажного окружения, и целостная образно-смысловая организация живописного мира художника разрушится. Лишь в органичном единстве их существования видится полнокровность бытия, мыслимая Пластовым как воплощение истины.

Круг традиционных принципов земного бытия включает и «семейственность», в какой-то мере отражающая важнейшие элементы праведности в христианской системе ценностей. Пластов использует этот мотив очень тактично, без вульгарной назидательности и суетливой демагогии. В картинах
«Из прошлого», «Мама», «Солнышко» сюжетная линия настойчиво, но ненавязчиво направляет на такую интерпретацию замысла художника.

В сакральной содержательности многих работ Пластова последнего периода с особой ясностью отразился духовный путь художника. В поздних произведениях мастера сокровенная сущность его мировоззрения отражается во всей полноте, где царят традиционные для русской культуры религиозные и эстетические взгляды, основанные на целостном восприятии мира и тяготеющие «к утверждению, а не рациональному аналитическому объяснению общей картины мира» ${ }^{8}$.

\section{Список литературы:}

1. Аркадий Александрович Пластов. Каталог произведений. - М.: Советский художник, 1976. 200 c.

2. Аркадий Александрович Пластов // Альбом. Сост. Н. Н. Пластов. Вступ. ст. Т. Ю. Пластова. - М.: Новый Эрмитаж, 2006. 368 с.

3. «Радостью бьется сердце...» // Художник. - 1972. - № 11. - СС. 19-34.

4. К Кауфман Р. С. Аркадий Александрович Пластов. - М.: Искусство, 1962. 30 с.

5. Козлов Ю., Авдонин А. Жизнь и судьба Аркадия Пластова. Документальный очерк. - Ульяновск: Симбирская книга, 1992. 120 с.

6. Костин В. Аркадий Александрович Пластов. - М.: Советский художник, 1956. 57 с.

7. Кузнецов В. Н. Аркадий Александрович Пластов и идеология позднего сталинизма // Творчество А. А. Пластова в контексте культуры ХХ века. - Ульяновск: УОХМ, 2004. С. 26.

8. Леняшин В. А. Дорога и путь в живописи XIX - XX веков // Дорога в русском искусстве / Альманах. Вып. 68. - СПб: Palace Editions, 2004. СС. 7-11.

9. Л Л Л Л РСФСР, 1985. $316 \mathrm{c}$.

10. Леонтьева Г. К. Аркадий Александрович Пластов. - Л.: Художник РСФСР, 1966. 71 с.

11. Лосский Н. О. Характер русского народа. Книга первая. Посев, 1957. 152 с.

12. Никифоров Б.М. Аркадий Александрович Пластов. - М.: Советский художник, 1972. $212 \mathrm{c}$.

13. Пластова Т. Аркадий Пластов. Православные истоки творчества // Русское искусство. - 2004. - № IV. - CC. $122-131$.

14. Третьяков Н. Н. Образ в искусстве. Основы композиции. Свято-Введенская Оптина Пустынь, 2001.264 с.

15. Филиппова И. И. Творчество Аркадия Пластова и проблемы изучения русского реализма // Проблемы советского искусства 1930-50 гг. (к 100-летию А.А.Дейнеки). - Курск, 1999. - СС. 82-91.

\section{References (transliteration):}

1. Arkadiy Aleksandrovich Plastov. Katalog proizvedeniy. - M.: Sovetskiy hudozhnik, 1976. 200 s.

2. Arkadiy Aleksandrovich Plastov // Al'bom. Sost. N. N. Plastov. Vstup. st. T. Yu. Plastova. - M.: Novyy Ermitazh, 2006. $368 \mathrm{~s}$.

3. «Radost'yu b’etsya serdce...» // Hudozhnik. - 1972. - № 11. - SS. 19-34.

4. Kaufman R. S. Arkadiy Aleksandrovich Plastov. - M.: Iskusstvo, 1962. $30 \mathrm{~s}$.

5. Kozlov Yu., Avdonin A. Zhizn' i sud'ba Arkadiya Plastova. Dokumental'nyy ocherk. - Ul'yanovsk: Simbirskaya kniga, 1992. $120 \mathrm{~s}$.

6. Kostin V. Arkadiy Aleksandrovich Plastov. - M.: Sovetskiy hudozhnik, 1956. 57 s.

7. Kuznecov V. N. Arkadiy Aleksandrovich Plastov i ideologiya pozdnego stalinizma // Tvorchestvo A. A. Plastova v kontekste kul'tury XX veka. - Ul'yanovsk: UOHM, 2004. S. 26.

8. Lenyashin V. A. Doroga i put'v zhivopisi XIX - XX vekov // Doroga v russkom iskusstve / Al'manah. Vyp. 68. - SPb: Palace Editions, 2004. SS. 7-11.

9. Lenyashin V. A. ...hudozhnikov drug i sovetnik. Sovremennaya zhivopis' i problemy kritiki. - L.: Hudozhnik RSFSR, 1985. $316 \mathrm{~s}$.

\footnotetext{
${ }^{8}$ Третьяков Н. Н. Указ. соч. С. 126.
} 
DOI: 10.7256/2222-1956.2013.4.9203

При цитировании этой статьи сноска на dоі обязательна

Культура и искусство 4(16) • 2013

10. Leont'eva G. K. Arkadiy Aleksandrovich Plastov. - L.: Hudozhnik RSFSR, 1966. 71 s.

11. Losskiy N. O. Harakter russkogo naroda. Kniga pervaya. Posev, 1957. $152 \mathrm{s.}$

12. Nikiforov B.M. Arkadiy Aleksandrovich Plastov. - M.: Sovetskiy hudozhnik, 1972. 212 s.

13. Plastova T. Arkadiy Plastov. Pravoslavnye istoki tvorchestva // Russkoe iskusstvo. - 2004. - № IV. - SS. 122-131.

14. Tret'yakov N. N. Obraz v iskusstve. Osnovy kompozicii. Svyato-Vvedenskaya Optina Pustyn', 2001. 264 s.

15. Filippova I. I. Tvorchestvo Arkadiya Plastova i problemy izucheniya russkogo realizma // Problemy sovetskogo iskusstva 1930-50 gg. (k 100-letiyu A.A.Deyneki). - Kursk, 1999. - SS. 82-91. 